\title{
Tetanus Toxin Antibody Levels in Pre-School Nigerian Children after Three Doses of Diphtheria-Pertussis-Tetanus/Pentavalent Immunization: A Cross-Sectional Study
}

\author{
Emmanuel E. Ekanem ${ }^{1}$, Helen 0. Uket ${ }^{2}$, Henry C. Okpara ${ }^{3}$ \\ ${ }^{1}$ Department of Paediatrics, University of Calabar and University of Calabar Teaching Hospital, Calabar, Nigeria \\ ${ }^{2}$ Department of Paediatrics, University of Calabar Teaching Hospital, Calabar, Nigeria \\ ${ }^{3}$ Department of Chemical Pathology, University of Calabar and University of Calabar Teaching Hospital, Calabar, Nigeria \\ Email: *profekanem@gmail.com
}

How to cite this paper: Ekanem, E.E., Uket, H.O. and Okpara, H.C. (2018) Tetanus Toxin Antibody Levels in Pre-School Nigerian Children after Three Doses of Diphtheria-Pertussis-Tetanus/Pentavalent Immunization: A Cross-Sectional Study. World Journal of Vaccines, 8, 39-52. https://doi.org/10.4236/wjv.2018.82005

Received: February 10, 2018

Accepted: May 5, 2018

Published: May 8, 2018

Copyright $\odot 2018$ by authors and Scientific Research Publishing Inc. This work is licensed under the Creative Commons Attribution International License (CC BY 4.0).

http://creativecommons.org/licenses/by/4.0/

\begin{abstract}
Background: Post-neonatal tetanus is an important problem. Prevention of tetanus in Nigeria is via immunization with three doses of Diphtheria-Pertussis-Tetanus (DPT)/Pentavalent vaccine at 6,10 and 14 weeks. The anti-tetanus antibody levels of these children are not known after they had received DPT3/Pentavalent vaccines. Aim: This work was to determine the anti-tetanus antibody (IgG) response in Nigerian children aged six months to five years who had received three doses of DPT vaccine in early infancy. Methods: Children aged six months to five years who were attended to in the University of Calabar Teaching Hospital for acute illnesses were recruited. Their anti-tetanus IgG levels were measured using Enzyme Linked Immunosorbent Assay (ELISA). The optimal cut-off level of $\geq 0.1 \mathrm{IU} / \mathrm{ml}$ was used as the protective level. Data was analysed using the Statistical Package for Social Sciences (SPSS) version 20.0 with simple proportions and percentages. Students' " $t$ " test and ANOVA were used to compare quantitative variables while Chi-square and Fisher's exact test were used to compare categorical data. Results: Four hundred and eighteen children participated in the study. The mean IgG antibody level was $1.021 \pm 0.9 \mathrm{IU} / \mathrm{ml}$. Four hundred children (95.7\%) had protective levels of antibodies. The highest proportion of subjects with protective levels was in infants, 6 - 11 months (99\%) and lowest in children aged 36 - 47 months (92.2\%). Conclusion: The proportion of children with protective levels was above $90 \%$ in all age groups studied. The current national immunization schedule is adequate. Further studies in older age groups are needful.
\end{abstract}




\section{Keywords}

DPT/Pentavalent Vaccine, Antibodies, Response

\section{Introduction}

Tetanus is a potentially fatal, acute, vaccine-preventable disease caused by an exotoxin produced by the bacterium Clostridium tetani. It occurs worldwide but is endemic in developing countries and has continued to be a significant public health problem in resource-poor nations including Nigeria [1] [2].

The World Health Organization (WHO) estimated a true global incidence of 700,000 to $1,000,000$ cases of tetanus per year resulting in 61,000 deaths in 2008 [3]. In 2010, the body identified tetanus as the highest mortality contributor to children after measles among vaccine preventable diseases [4]. In 2012, six cases of tetanus were reported in the United Kingdom, 37 cases in the USA but 112 cases in Nigeria [5]. In 2013, there were 23 cases in the USA, none in South Africa but 556 cases in Nigeria [5]. Annually, tetanus causes 309,000 deaths [6]. Post-neonatal tetanus caused 36,806 deaths in 2015 [7].

Post neonatal tetanus is an important problem in Nigeria [8] [9] [10] [11] [12]. Most studies have recognized tetanus beyond the neonatal period as a problem of enormous consequence with high case fatality rate [10] [13] [14], yet it is still seemingly disregarded and continues to afflict several children in this millennium [8] [12] [15].

The WHO recommends administration of three doses of tetanus toxoid as routine immunisation programme to all infants and booster doses during adolescence and pregnancy in order to achieve elimination of tetanus in early childhood [16]. Many countries in sub-Saharan Africa are implementing this recommendation and have either attained the elimination of tetanus or made substantial progress towards achieving this goal but some are not [17]. In Nigeria, primary vaccination in the National Programme on Immunization (NPI) is positioned at 6 weeks, 10 weeks and 14 weeks with no booster doses given during at adolescence [18].

The Paediatric Association of Nigeria (PAN) developed a more comprehensive National routine immunization schedule for the country and recommended it to the Government. They considered early exposure of Nigerian children to infection, low response to too early and short interval primary vaccination series and the greater need for boosting and recommended booster doses at $12-15$ months of age, 5 years of age and subsequently, every 10 years [19]. This is yet to be implemented and there is no data generated to provide evidence for the recommendation.

Immunization status has been normally evaluated from the immunization history reported by the caregiver/parent which may not be correct [20] [21]. This leads to over or under prescription of the vaccine. The determination of 
serum anti-tetanus antibody levels provides scope for an objective analysis of tetanus immunity [22].

Serological surveys have been strongly encouraged to appraise the impact of vaccination programs, improve immunization policies and reduce the disease burden [10]. The main outcome measure of this present study is the determination of anti-tetanus antibody titres in Nigerian children aged six months to sixty months who had received the complete schedule of primary vaccination according to the NPI schedule.

\section{Subjects and Methods}

\subsection{Study Location}

The study was carried out in the University of Calabar Teaching Hospital (UCTH), Calabar, Cross River State. Cross River State is situated in the south-south geopolitical zone of Nigeria. Calabar, the state capital has two Local Government Areas (Calabar Municipality and Calabar South). University of Calabar Teaching Hospital is a tertiary health facility in the Calabar Municipality Local Government Area.

\subsection{Sample Size Determination}

In a prospective study conducted by Orimadegun et al. [22] among 304 hospitalised children aged one to nine years in Ibadan, Oyo State, the prevalence of protective immunity against tetanus using enzyme-linked immunosorbent assay (ELISA) after three doses of DPT vaccine was $44.7 \%$ [22]. This prevalence rate was used in this study to derive the sample size of a minimum of 380 children.

\subsection{Patient Recruitment and Selection Criteria}

This study was conducted in the Department of Paediatrics, UCTH. The Department has four service sections: the Children Outpatient Clinic (CHOP), the Newborn Unit, the Children Emergency Room (CHER) and the Paediatric Ward. Well-nourished children (those with weight-for-height $>-1, \mathrm{z}$-score $>$ 90\%) [23] between the ages of six months and five years who were attended to in CHOP, CHER and Ward for acute illnesses and had met the inclusion criteria were recruited. Immunization cards were inspected to identify those who had completed three doses of Diphtheria-Pertussis-Tetanus (DPT)/Pentavalent vaccine for final eligibility. The last date of DPT/Pentavalent vaccines was noted and blood samples were then taken for determination of IgG levels. Only well-nourished children with no past history of tetanus were recruited. Children with chronic illnesses were excluded.

\subsection{Ethical Issues}

Ethical Approval: ethical clearance for the conduct of this study was obtained from the Ethics Committee of the University of Calabar Teaching Hospital with letter reference number UCTH/HREC/33/258. 


\subsection{Informed Consent}

Parents or guardians of children in the different paediatric wards were given a copy of the statement of the study which they read to gain a good understanding of the nature of the study. They had the unconditional option of giving or declining consent for participation of their child or ward. For parents that were not able to read, the researcher explained the nature of the study to them in details. The screening form for eligibility was given to them to fill to select those eligible for the study. The non-negative consequences of withdrawing a child or ward from the study were elaborately explained to parents or guardians.

\subsection{General Clinical Assessment of Subjects}

Following informed consent obtained from parents or guardians, the child's bio-data and information on present illness, the past medical and immunisation history were obtained from the subjects by use of a semi-structured questionnaire. Immunization status was confirmed for each child by visualizing the card via physical presentation of the card at the clinic, social media presentation or home acquisition of the card. Those whose cards were unavailable were excluded.

\subsection{Patient Preparation, Specimen Collection and Preservation}

The specimen collection procedure was explained to the parents or guardians prior to venepuncture. Three millilitres $(3 \mathrm{mls})$ of venous blood was obtained from each eligible child under aseptic procedure into a clean plain non-anticoagulated sample bottle and allowed to clot. The samples were transported in a cooler of ice to the paediatric side laboratory within one to two hours of collection. The clotted sample was centrifuged at $5000 \mathrm{rpm}$ for five minutes. The supernatant serum was separated and transferred to storage tubes and stored at $-20^{\circ} \mathrm{C}$ for maximum of a week before batch analysis. Labelling was done with coded numbers to avoid mistakes. The samples were analysed using an ELISA test kit (Tetanus toxin IgG, DRG International, Inc., Marburg, Germany) [24]. The kit was stored and preserved at a refrigerator temperature of $2^{\circ} \mathrm{C}$ to $8^{\circ} \mathrm{C}$ till completion of the study.

\subsection{Interpretation of Results}

The manufacturer kit-dependent protective antibody level using this assay was $\geq 0.1 \mathrm{IU} / \mathrm{ml}[24]$.

\subsection{Analytical Quality Control}

The concentrations of anti-tetanus toxoid antibody in the negative and positive control sera were read from the calibration curve. Calibrators and controls were included in each run. The obtained values were compared with the range given on the national Quality Control (QC) certificate. Curve shape was similar to the calibration curve shown in the QC certificate. Acceptable run was determined 
with control values that fell within expected range of values as given on the QC certificate.

\subsection{Data Analysis}

The data obtained was analysed using Statistical Package for Social Sciences (SPSS) version 20.0. Data was coded and entered into Microsoft Excel spread sheet and later imported into SPSS for cleaning and analysis. Descriptive statistics with the use of frequencies, percentage/proportions mean and standard deviation was used to summarize data. Inferential statistics with the use of Chi square and Fisher exact tests (for qualitative data) and Student's t-test (for quantitative variables) were used to test for association between bivariate at $5 \%$ level of significance. Differences between mean values of antibody levels after three doses DPT between the different age groups were compared using F-test (ANOVA). A p-value of less than 0.05 was considered statistically significant.

\section{Results}

\subsection{Socio-Demographic Characteristics of Study Participants}

\subsubsection{Age and Sex Distribution of Study Participants}

Table 1 shows the differences in age groups between male and female participants. A total of 418 children aged 6 to 60 months participated in the study. Out of these 219 (52.4\%) were males while 199 (47.6\%) were females, giving a male: female ratio of 1.1:1. The mean age of study participants was $24.7 \pm 16.1$ months. The mean age of the male and female study participants were 24.2 months and 25.3 months respectively $(t=0.71 ; \mathrm{p}>0.05)$.

\subsubsection{Mean Antibody Levels to Tetanus Toxin}

Table 2 shows the mean antibody levels to tetanus toxin in subjects who had received three doses of DPT in early infancy. Overall, the mean value was $1.0 \pm 0.9$ IU/ml (Range: 0.0 to 4.1 ). The highest mean antibody level was among those aged 48 to 60 months while the lowest level was among the 12 to 23 months age group $(\mathrm{p}<0.001)$. The mean antibody levels of males were higher than females but the difference was not statistically significant $(\mathrm{p}=0.493)$.

Table 1. Age and sex distribution of study participants.

\begin{tabular}{cccc}
\hline \multicolumn{3}{c}{ Sex } \\
\hline Age group (months) & Male & Female & Total \\
& N (\%) & N (\%) & N (\%) \\
\hline 6 to 11 & $53(12.7)$ & $43(10.3)$ & $96(23.0)$ \\
12 to 23 & $60(14.4)$ & $56(13.4)$ & $116(27.8)$ \\
24 to 35 & $53(12.7)$ & $45(10.8)$ & $98(23.4)$ \\
36 to 47 & $25(6.0)$ & $26(6.2)$ & $51(12.2)$ \\
48 to 60 & $28(6.7)$ & $29(6.9)$ & $57(13.6)$ \\
Total & $219(52.4)$ & $199(47.6)$ & $\mathbf{4 1 8}(100.0)$ \\
\hline
\end{tabular}

Chi-square $=0.915, \mathrm{df}=4, \mathrm{p}=0.922$. 
Table 2. Mean antibody levels to tetanus toxin by age group.

\begin{tabular}{|c|c|c|c|c|c|}
\hline Variable & $\begin{array}{l}\text { Frequency } \\
(\mathrm{N}=418)\end{array}$ & Mean & $\mathrm{SD}^{*}$ & Statistics & p-value \\
\hline \multicolumn{6}{|c|}{ Age (months) } \\
\hline 6 to 11 & 96 & 0.9 & \pm 0.7 & $\mathrm{~F}(\mathrm{ANOVA})=9.508$ & $<0.001^{*}$ \\
\hline 12 to 23 & 116 & 0.8 & \pm 0.7 & & \\
\hline 24 to 35 & 98 & 1.3 & \pm 1.0 & & \\
\hline 36 to 47 & 51 & 1.0 & \pm 1.0 & & \\
\hline 48 to 60 & 57 & 1.4 & \pm 1.0 & & \\
\hline \multicolumn{6}{|l|}{ Sex } \\
\hline Male & 219 & 1.1 & \pm 0.9 & $\begin{array}{l}\text { Student } t \text {-test } \\
\quad(t=0.686)\end{array}$ & 0.493 \\
\hline Female & 199 & 0.9 & \pm 0.8 & & \\
\hline Total & $N=418$ & 1.0 & \pm 0.9 & & \\
\hline
\end{tabular}

$\mathrm{SD}^{*}=$ Standard deviation.

Table 3 shows the post hoc comparisons of the mean antibody levels according to age group. The children aged 24 to 35 months and 48 to 60 months had mean antibody levels significantly higher than that of lower age groups $(\mathrm{p}=$ 0.0001).

\subsubsection{Relationship between Sociodemographic Characteristics and Stratified Anti-Tetanus Antibody Levels}

Antibody levels were empirically grouped into various concentrations viz.; $<0.1$ $\mathrm{IU} / \mathrm{ml}, 0.1$ to $0.5 \mathrm{IU} / \mathrm{ml},>0.5$ to $1.1 \mathrm{IU} / \mathrm{ml}$ and $>1.1$ to $5.0 \mathrm{IU} / \mathrm{ml}$.

Table 4 shows the number of study subjects who had antibody titres in the stated concentration ranges. Levels equal and above $0.1 \mathrm{IU} / \mathrm{ml}$ were accepted as protective while levels of lower titres were defined as non-protective. Of the 418 subjects, 400 (95.7\%) had antibody levels above $0.1 \mathrm{IU} / \mathrm{ml}$ while 18 (4.3\%) subjects had antibody levels below $0.1 \mathrm{IU} / \mathrm{ml}$.

\subsubsection{Proportion of Study Participants by Age Group with Protective Levels of Antibody}

Figure 1 depicts the proportion of study participants by age group with protective antibody levels $(\geq 0.1 \mathrm{IU} / \mathrm{ml})$. All the proportions were above $90 \%$. There was no consistent trend in the proportion of subjects with protective levels in relation to age. It reduced from a peak of $99 \%$, minimally increased, reduced and finally increased in the older age group. The highest frequency of subjects with protective antibody levels was found in the infants and lowest among children aged 36 to 47 months. However, the difference in proportion was not statistically significant $(\mathrm{p}=0.345)$.

\section{Discussion}

This study revealed that the proportion of subjects with protective anti-tetanus 
Table 3. Post hoc comparison of mean values of antibody levels among age groups.

\begin{tabular}{ccc}
\hline $\begin{array}{c}\text { Reference Age groups } \\
\text { (months) }\end{array}$ & $\begin{array}{c}\text { Other age groups } \\
\text { (months) }\end{array}$ & p-value \\
\hline & 12 to 23 & 1.000 \\
6 to 11 & 24 to 35 & $0.0001^{*}$ \\
& 36 to 47 & 1.000 \\
& 48 to 60 & $0.0001 *$ \\
& 24 to 35 & $0.0001^{*}$ \\
& 36 to 47 & 0.574 \\
& 48 to 60 & $0.0001^{*}$ \\
& 36 to 47 & 0.922 \\
24 to 35 & 48 to 60 & 1.000 \\
& 48 to 60 & 0.096 \\
\hline
\end{tabular}

* = Statistically significant $(\mathrm{p}<0.05)$.

Table 4. Spread of study subjects across various antibody concentration ranges.

\begin{tabular}{ccc}
\hline Antibody level IU/ml & N & \% of Total \\
\hline$<0.1$ & 18 & 4.3 \\
0.1 to 0.5 & 151 & 36.1 \\
$>0.5$ to 1.1 & 92 & 22.0 \\
$>1.1$ to 5.0 & 157 & 37.6 \\
All & 418 & 100.0 \\
\hline
\end{tabular}

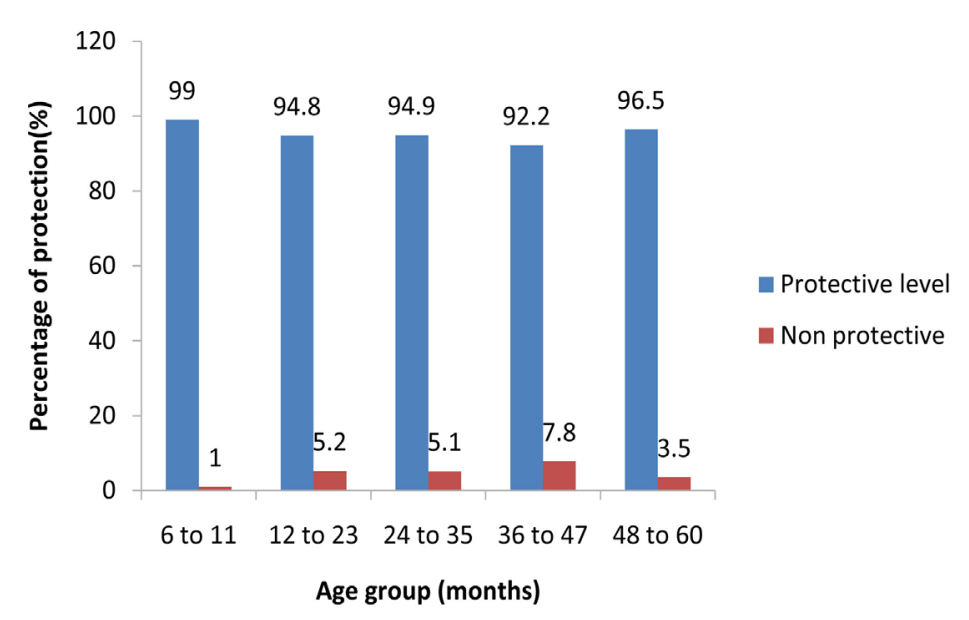

Figure 1. Proportion of study participants by age group with protective levels.

antibody levels was $95.7 \%$ using the gold standard (ELISA) method. This prevalence is similar to $99.6 \%$ reported by Gergen et al. [25] among a group of Mexican American children aged 4 to 11 years. The prevalence was higher than the 44.7\% reported by Orimadegun et al. [22] in Ibadan, south west Nigeria, among children aged 1 to 9 years. The higher proportion in the current study could be due to the fact that the subjects were younger and would not have experienced as 
much decay in antibody levels as the Ibadan study that recruited older subjects [22].

The study showed that the overall mean anti-tetanus antibody level of the children was above the optimal protective level of $\geq 0.1 \mathrm{IU} / \mathrm{ml}$. The mean antibody level in each age group was also above the optimal cut-off. It is therefore apparent that three doses of tetanus toxoid received as primary vaccination in early infancy was sufficient to maintain adequate serum antibody levels in the age group studied. The eighteen children with suboptimal levels are at risk of tetanus. This may reflect the proportion of similarly affected children in the general population. It was not within the scope of the present study to investigate the reasons for low antibody levels in affected subjects. Considering that herd immunity is not relevant to tetanus, the target is to achieve protection of all vulnerable subjects. This is important while taking a decision on the introduction of booster doses.

The present study also showed that the highest mean antibody level was found in the older age group of 48 to 60 months. This may probably be due to subclinical exposure of the older age groups who are likely to ambulate more and sustain injuries.

Mean antibody levels and the pattern of the proportion of children with protective levels in the current study did not follow any progressive age-related trends as has been reported in earlier studies [8] [13] [26] [27]. It declined marginally, increased, declined and increased again. In spite of this lack of consistent trend, it is clear that the chances of having low tetanus antibody levels were least in infancy and highest in older under- 5 children as a group. The explanation for the deviation from expected trend is not too obvious. It may be argued that the best evidence for assessing age-related trends in antibody levels should be from a longitudinal follow-up of a cohort of vaccinated subjects. A cross-sectional study such as the present one may give a fair representation but not necessarily a perfect age-related relationship.

It is pertinent to discuss the findings of the current study with respect to the need or otherwise for booster doses. Given the high percentage of children with protective antibody levels in late infancy, it is reasonable to suggest that there is no need for a booster during this period of life. While the proportion of subjects with suboptimal antibody levels increased in the second through the fifth year of life, more than $90 \%$ still had optimal levels. It would therefore also be difficult to support a recommendation of blanket booster doses of tetanus toxoid for this category. Multicentre, collaborative studies across the country would be necessary to get a nationally representative pattern. However, the decision to introduce or withhold booster doses should not be based on proportion of people with protective antibody levels alone. Since the benefits of herd immunity do not apply to tetanus, the aim should be to extend protection to every susceptible subject.

The present study showed that the proportion of children that were protected 
in each age group was above $90 \%$. Infants had the highest proportion of protection. In addition, this study showed an increase in the proportion of subjects with protective antibody levels in children aged 48 to 60 months as compared with those aged 36 to 47 months. The reason for the increase is not clear. The World Health Organization has shown that immunization of infants with three doses of DPT vaccine provides tetanus immunity for one to three years [16] [28]. This should give the children protection till age one to three years. This study has shown that the tetanus immunity of some subjects who had received three doses of DPT in early infancy can last up to five years. Most of the children with post-neonatal tetanus in Nigeria have been children who were not immunized at all [8] [9] [10] [11] [12]. It may be argued that at face value, booster doses of tetanus toxoid are not required within five years of primary vaccination. However, the consequence of this argument is that those subjects with suboptimal levels will be unprotected, particularly as herd immunity does not apply to tetanus.

\section{Conclusion}

The anti-tetanus antibody response of study subjects to vaccination in early infancy was satisfactory as the overall proportion of the children with reliable protection was $95.7 \%$. The mean antibody level was highest in the age group of 48 to 60 months. Infants constituted the highest proportion of children with protective antibody levels: $99 \%$ of infants had optimal levels. The problem of post-neonatal tetanus in Nigeria may be related more to non-immunization than antibody response to immunization.

\section{Recommendations}

The current national immunization schedule which includes three doses of tetanus toxoid received as primary vaccination in early infancy is adequate as it maintains serum antibody levels but should be strengthened to ensure universal coverage. Further studies are recommended in the older age group in view of the fact that tetanus immunity can last up to five years as seen in this study. This was a cross-sectional study and as such could not provide information as to the rate of decay of antibodies over time. This information can best be provided by a longitudinal study.

\section{Limitation of Study}

This was a cross-sectional study and as such could not provide information as to the rate of decay of anti bodies over time. In addition, it was a hospital based study and may therefore not necessarily represent the true picture of the general population.

\section{References}

[1] CDC. (2012) Epidemiology and Prevention of Vaccine-Preventable Diseases. In: 
CDC, Eds., The Pink Book, 12th Ed., Public Health Foundation, Washington DC, 291-300. http://www.cdc.gov/vaccines/pubs/pinkbook/tetanus.html

[2] Ramos, J., Reyes, F. and Tesfamariam, A. (2008) Tetanus in a Rural Ethiopian Hospital. Tropical Doctor, 38, 104-105. https://doi.org/10.1258/td.2006.006085

[3] World Health Organization. (2008) Vaccine-Preventable Diseases: Monitoring Systems. Global Summary.

[4] World Health Organization. (2017) Vaccine-Preventable Diseases: Monitoring System 2010 Global Summary. Immunization, Vaccines and Biologicals. http://whqlibdoc.who-int/hq/2010/WHO IVB 2010 eng.pdf

[5] World Health Organization. (2014) Vaccine-Preventable Diseases: Monitoring System. Global Summary.

[6] Pascual, F., McGinley, E., Zanardi, L., Cortese, M. and Murphy, T. (2003) Tetanus Surveillance, United States. MMWR Surveillance Summary, 52, 1-8.

[7] Kyu, H., Mumford, J. and Naghavi, M. (2017) Mortality from Tetanus between 1990 and 2015: Findings from the Global Burden of Disease Study 2015. BMC Public Health, 17, 179. https://doi.org/10.1186/s12889-017-4111-4

[8] Oyedeji, O.A., Fadero, F., Joel-medewase, V., Elemile, P. and Ademola, G. (2012) Trends in Neonatal and Post-Neonatal Tetanus Admissions at a Nigerian Teaching Hospital. Journal of Infectious Diseases, 6, 847-853.

https://doi.org/10.3855/jidc.2105

[9] Gbadegesin, R., Adeyemo, A. and Osinusi, K. (1996) Childhood Post-Neonatal Tetanus. Nigerian Journal Paediatrics, 23, 11-15.

[10] Anah, M., Etuk, I., Ikpeme, O., Ntia, H., Ineji, E. and Archibong, R. (2008) Post-Neonatal Tetanus in Calabar, Nigeria: A 10 Year Review. Nigerian Medical Practitioner, 54, 45-47.

[11] Oyelami, O., Aladekomo, T. and Ononye, F. (1996) A 10 Year Retrospective Evaluation of Cases of Post-Neonatal Tetanus Seen in a Pediatric Unit of a University Teaching Hospital in South Western Nigeria. Central African Journal of Medicine, 42, 73-75.

[12] Chukwuka, O., Ezeudu, C. and Nnamani, K. (2015) Neonatal and Post-Neonatal Tetanus in Nnamdi Azikiwe University Teaching Hospital, Nnewi, South-East, Nigeria: A 10-Year Review. Tropical Journal of Medical Research, 18, 30-33. https://doi.org/10.4103/1119-0388.152552

[13] Emodi, I.J., Bch, M.B., Ikefuna, A.N. and Obichukwu, C. (2011) Incidence and Outcome of Neonatal Tetanus in Enugu over a 10-Year Period. South African Journal of Community Health, 5, 117-119.

[14] Ide, L. and Uchenwa-Onyenegecha, T. (2016) Post Neonatal Tetanus: 20 Years Experience as Seen at the University of Port Harcourt Teaching Hospital. British Journal of Medicine and Medical Research, 12, 1-5. https://doi.org/10.9734/BJMMR/2016/19047

[15] Ojini, F. and Danesi, M. (2005) Mortality of Tetanus at the Lagos University Teaching Hospital, Nigeria. Tropical Doctor, 35, 178-181. https://doi.org/10.1258/0049475054620806

[16] Borrow, R., Balmer, P. and Roper, M. (2006) The Immunologic Basis for Immunization Series-Module 3: Geneva, Switzerland, 2007.

[17] UNICEF/WHO/UNFPA (2000) Maternal and Neonatal Tetanus Elimination by 2005: Strategies for Achieving and Maintaining Elimination. New York.

[18] Federal Ministry of Health (2006-2010) Comprehensive NPI Multi-Year Plan. 
[19] Immunisation PAC on (2012) Paediatric Association of Nigeria (PAN) Recommended Routine Immunization Schedule for Nigerian Children. Nigerian Journal of Paediatrics, 39, 152-158.

[20] Stubbe, M., Mortelmans, L., Desruelles, D., Swinnen, R., Vranckx, M. and Brasseur, E. (2007) Improving Tetanus Prophylaxis in the Emergency Department: A Prospective, Double-Blind Cost-Effectiveness Study. Emergency Medicine Journal, 24, 648-653. https://doi.org/10.1136/emj.2007.048520

[21] Simonsen, O., Bentzoss, M. and Heron, I. (1986) ELISA for the Routine Determination of Antitoxin Immunity to Tetanus. Journal of Biological Standards, 14, 231-239. https://doi.org/10.1016/0092-1157(86)90008-9

[22] Orimadegun, A.E., Orimadegun, B.E. and Akinlolu, A. (2013) Immunity against Tetanus Infection, Risk Factors for Non-Protection, and Validation of a Rapid Immunotest Kit among Hospitalized Children in Nigeria. Frontiers in Neurology, 4, 142-143. https://doi.org/10.3389/fneur.2013.00142

[23] World Health Organization (2006) Child Growth Standards: Length/Height for Age, Weight-for-Age, Weight-for-Length, Weight-for-Heigth and Body Mass Index-for-Age, Methods and Development. Geneva.

[24] DRG Instruments GmbH G. Tetanus Toxin IgG ELISA.

[25] Gergen, P.J., Ezzati-Rice, T.M. and Russell, H. (1988) DTP Immunization Status and Tetanus Antitoxin Titers of Mexican American Children Ages Six Months through Eleven Years. American Journal of Public Health, 78, 1446-1450. https://doi.org/10.2105/AJPH.78.11.1446

[26] Fatunde, O. and Familusi, J. (2001) Post-Neonatal Tetanus in Nigeria-A Need for Booster Doses of Tetanus Toxoid. Nigerian Journal of Paediatrics, 28, 35-38. https://doi.org/10.4314/njp.v28i2.12053

[27] Adekanle, O., Ayodeji, O. and Olatunde, L. (2009) Tetanus in a Rural Setting of South-Western Nigeria: A Ten-Year Retrospective Study. Libyan Journal of Medicine, 4, 78-80.

http://www.pubmedcentral.nih.gov/articlerender.fcgi?artid=3066715\&tool=pmcent $\underline{\text { rez\&rendertype }=\text { abstract }}$

[28] European Centre for Disease Prevention and Control (2009) Scientific Panel on Childhood Immunisation Schedule: Diphtheria-Tetanus-Pertussis (DTP) Vaccination. Stockholm, 1-23. http://www.ecdc.europa.eu 


\section{Appendix I}

\section{HEALTH RESEARCH ETHICS COMMITTEE UNIVERSITY OF CALABAR TEACHING HOSPITAL}

\section{P. M. B. 1278 , CALABAR, NIGERIA}

CHIEF MEDICAL DIRECTOR:

Dr. Thomas U. Agan

B.Med, SC (Anat), MB, FWACS, FMCOG, FCAI

CHAIRMAII

Prof. Martin Meremikwu

MB, BCH, MSC, FMC, Paed.

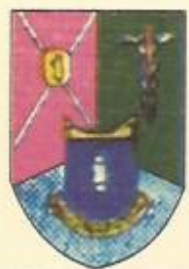

CHARMAM, MEDICAL ADVISORY COMHIrTEE

Dr. Queeneth Kalu

MBBCH, DA (WACS), DA (WFSA)

SECRETIMR:

Ededet Eyoma Esq.

BA, LLB, BL, MPA, DIP-Comp. Sc, ANIM, AIHSAN

Our Ref:

Your Ref:

Date: $11^{\text {TH }}$ AUGUST,2014

NOTICE OF FULL APPROVAL OF PROTOCOL

TETANUS TOXIN ANTIBODY LEVELS IN PRESCHOOL NIGERIAN

CHILDREN AFTER THREE DOSES OF DIPHTHERIA-PERTUSIS-

TETANUS IMMUNISATION: HOSPITAL BASED STUDY

UCTH HEALTH RESEARCH ETHICS COMMITTEE REG. NUMBER:

NHREC/07/10/2012

Health Research Ethics Committee Protocol Assigned Number:

UCTH/HREC/33/258

Name of principal investigator:

UKET H. $O$

Address of Principal Investigator

DEPARTMENT OF PAEDIATTRICS UCTH, CALABAR

Date of Receipt of Valid Application:

$8^{\text {TH }}$ JUNE, 2014

Date of Meeting where determination of Research was made:

$11^{\mathrm{TH}}$ AUGUST, 2014

This is to inform you that the Research described in the submitted protocol, the Consent Forms, and other participant information materials have been reviewed and given full approval by the Health Research Ethics Committee.

This approval dates from $11^{\text {th }}$ August, 2014 to $10^{\text {th }}$ July, 2015. If there is delay in starting the research, please inform the HREC so that the dates of approval can be adjusted accordingly. Note that no participant accrual or activity related to this research may be conducted outside of these dates. In multi year research, endeavour to submit your annual report to the HREC early in order to obtain renewal of your approval and avoid disruption of your research.

The National Code for Health Research Ethics requires you to comply with all institutional guidelines, rules and regulations and with the tenets of the Code including ensuring that all adverse events are reported promptly to the HREC. No changes are permitted in the research without prior approval by the HREC except in circumstances outlined in the code. The HREC reserves the right to conduct compliance visit to your research site without previous notification.

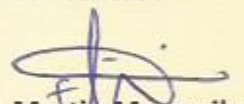

Prof. Martih/Meremikwu

CHAIRMAN, UCTH HREC 


\section{Appendix II}

\section{HEALTH RESEARCH.ETHICS COMMITTEE UNIVERSITY OF CALABAR TEACHING HOSPITAL}

CHIEF MEDICAL DIRECTOR:

Dr. Thomas U. Agan

B.Med, SC (Anat), MB, FWACS, FMCOG, FCAI CHAIRMAII

Prof. Martin Meremikwu

MB, BCH, MSC, FMC, Paed.
P. M. B. 1278 , CALABAR, NIGERIA

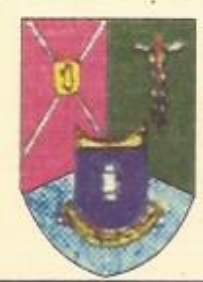

CHAIRMAM, MEDICAL ADVISORY COMMITTEE

Dr. Queeneth Kalu

MBBCH, DA (WACS), DA (WFSA)

SECRTIARY:

Ededet Eyoma Esq.

BA, LLB, BL, MPA, DIP-Comp. Sc, ANIM, AIHSAN

Our Ref:

$9^{\text {th }}$ Jan., 2017

Date:

Your Ref:

Dr. Helen Omini Uket

Department of Paediatrics

University of Calabar Teaching

Hospital, Calabar.

\section{RE: APPLICATION FOR EXTENSION/RENEWAL OF ETHICA} APPROVAL

The ethical approval granted for the conduct of your research on "TETANUS TOXIN ANTIBODY LEVELS IN PRESCHOOL NIGERIAN CHILDREN AFTER THREE DOSES OF DIPHTHERIA-PERTUSIS-TETANUS IMMUNISATION: HOSPITAL BASED STUDY" (REF. UCTH/HREC/33/258) is hereby renewed for 12 months with effect from your date of application $14^{\text {th }}$ December, 2016.

Thank you.

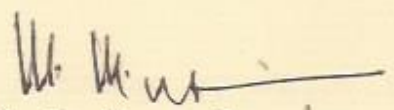

Martin Meremikwu

Chairman HREC 


\section{Appendix III}

\section{INFORMATION SHEET}

(Statement of the study)

TETANUS ANTIBODY LEVELS IN PRESCHOOL NIGERIAN CHILDREN AFTER THREE DOSES OF DIPHTHERIA-PERTUSSIS-TETANUS (DPT) IMMUNIZATION

\section{TO PARENT/GUARDIAN}

Dear Sir/Madam,

I am a paediatrician (a doctor that treats children) working in the Department of Paediatrics, University of Calabar Teaching Hospital. My name is Dr Uket, Helen Omini. My phone number and email address are 08059000969 and helenuket2016@gmail.com respectively.

I wish to let you know that your child/ward has been selected to participate in a study titled, "Tetanus antibody levels in preschool Nigerian children after three doses of DPT immunization".

We want to find out if the level of antibody in your child/ward can protect your child/ward.

Every child selected to participate in this exercise will be examined by a doctor. Three millilitres of blood will be collected for this study from each child and this will cause a brief moment of pain. This study would help us identify children with non-protective levels and policy makers will be informed to know exactly when these children would require another vaccination after the third dose of DPT to reduce the incidence in the general population.

You are to freely decide whether your child/ward should participate in this exercise or not after reading/understanding the information provided in this sheet or the verbal explanation if you are unable to read. If you are unable to sign; your thumbprint will be obtained in lieu of your signature. Refusal to allow your child or ward participate in this exercise will not have a negative effect on the child or his care whatsoever.

\section{Appendix IV}

\section{INFORMED CONSENT FORM \\ VOLUNTARY PARTICIPATION: \\ TETANUS ANTIBODY LEVELS IN PRESCHOOL NIGERIAN CHILDREN AFTER THREE DOSES OF DIPHTHERIA-PERTUSSIS-TETANUS (DPT) IMMUNIZATION}

I ------------------ parent/guardian of --------------- have carefully read the information provided to me and fully understand all the points. I hereby consent to my child's/ ward's participation in the exercise.

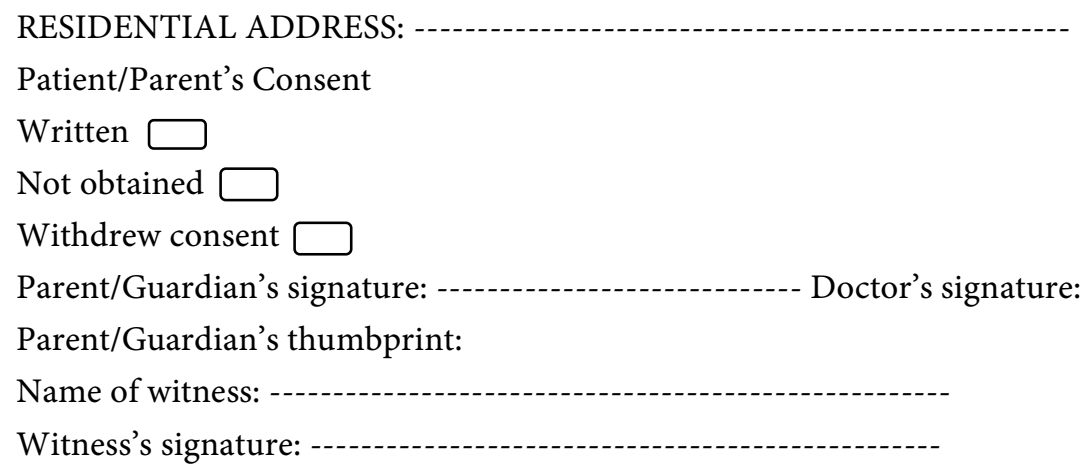

